\title{
PLIABILITY AS AN EXPERIENTIAL QUALITY: EXPLORING THE AESTHETICS OF INTERACTION DESIGN
}

Jonas Löwgren, Malmö University

Digital design materials are temporal as much as they are spatial, which means that specific concepts are needed for understanding the use experiences of digital artifacts and the aesthetics of interaction design. In this paper, the quality of pliability is introduced to characterize the degree to which interaction feels involving, malleable, and tightly coupled - and hence to what degree it facilitates exploration and serendipity in use. Three sets of contrasting artifact examples from different domains (online maps, digital-image management, and online thesauri) are analyzed with regard to pliability. It is argued that the use of everyday digital products, normally perceived as instrumental and utility oriented, has an important experiential-aesthetic dimension consisting of temporal and visuo-tactile qualities (including pliability). The paper concludes with a discussion of related work and the role of experiential qualities in interaction design.

Keywords: aesthetics of interaction, experiential quality, interaction design, pliability

\section{INTRODUCTION}

Interaction design refers to the shaping of digital materials - software, electronics, telecommunication, etc. - with a particular focus on the use of the resulting digital artifacts. Websites, mobile phones, cross-media entertainment, locationbased information in public spaces, e-commerce, interactive art installations, medical rehabilitation technology, business administration software ... these are a few examples of products and services that interaction designers may concern themselves with.

Interaction design is a multidisciplinary field with an influential heritage from software engineering and applied psychology (including labels such as human factors, humancomputer interaction $[\mathrm{HCl}]$, and cognitive ergonomics). More recently, attempts have been made to treat interaction design as a design

This paper starts from two observations. First, that there seems to be growing recognition in interaction design that there is something to learn from the more mature design disciplines in thinking about the user/ customer as a whole person with senses, feelings and desires. Second, that interaction design deals with a material with rather unique properties: Digital design materials are both genuinely temporal and genuinely spatial.

The first observation merely means that there is a need for systematic knowledge construction in interaction design on qualities other than efficiency, relevance, and fitnessfor- purpose. The second observation, however, deserves a bit of elaboration.

The spatial properties of a digital artifact are undeniable - it occupies a two-dimensional screen surface or a three-dimensional product shape; it has two- or three-dimensional form. To the (limited) extent that interaction design has concerned itself with issues of form, the main input so far has come from graphic design and industrial design. And to be sure, some genres of interaction design are predominantly spatial. There are physical devices with digital functions of low complexity, such as remote controls where buttons are mapped to functions in stateless interaction, which can be beneficially treated as pure industrial design projects. Some types of websites work well as sequences of graphic designs stringed together with the coarsegrained interaction of page-topage hyperlinks.

However, we have all experienced the differences between watching a screenshot or a photograph of a digital artifact, and trying it out for real. The feel of the interaction, the hints of complexity unfolding as different options are explored, the rhythm of the initiative shifting back and forth, the sense of understanding and insight growing over time, the sometimes almost dramaturgical orchestration of the interaction from conflict to resolution - all of this is part of the temporal and visuo-tactile properties of using the digital artifact. With a slight simplification, we might say that graphic-design and industrialdesign products carry much of their meaning on the surface whereas interaction design products hide much of their meaning in virtual "contents" to 
emerge only in sustained interaction. The point is that interaction design needs to develop its own body of knowledge on desirable qualities of the use experience, qualities that take into account the synthesis of temporal and spatial that characterizes digital artifacts. Another way of putting it would be to say that we need to start articulating the aesthetics of interaction design.

I use the word "aesthetic" here in a pragmatist sense, drawing on Dewey's (1934) characterization of an aesthetic experience as something that integrates emotional, sensate, and cognitive aspects into an immediate whole. Dewey sketches a continuum of everyday experiences ranging from the mundane to the aesthetic, rather than confining aesthetics to galleries and other institutionally refined settings. Aesthetic experiences answer to our needs for a sense of meaning and wholeness, and push us over the threshold of doing something for its own sake. As Petersen et al. (2004) point out, aesthetic experience in this sense spans the analytical mind and the bodily experience. Further, I share Fels's (2000) position that people have aesthetic experiences when they manipulate objects skillfully (see also McCullough, 1996).

In this paper, I shall be concerned with one specific example of aesthetic experience in the use of digital artifacts. I propose the concept of pliability as a way to characterize a specific experiential quality, outline it by means of examples and discussion, and then discuss its scope and relevance for interaction design.
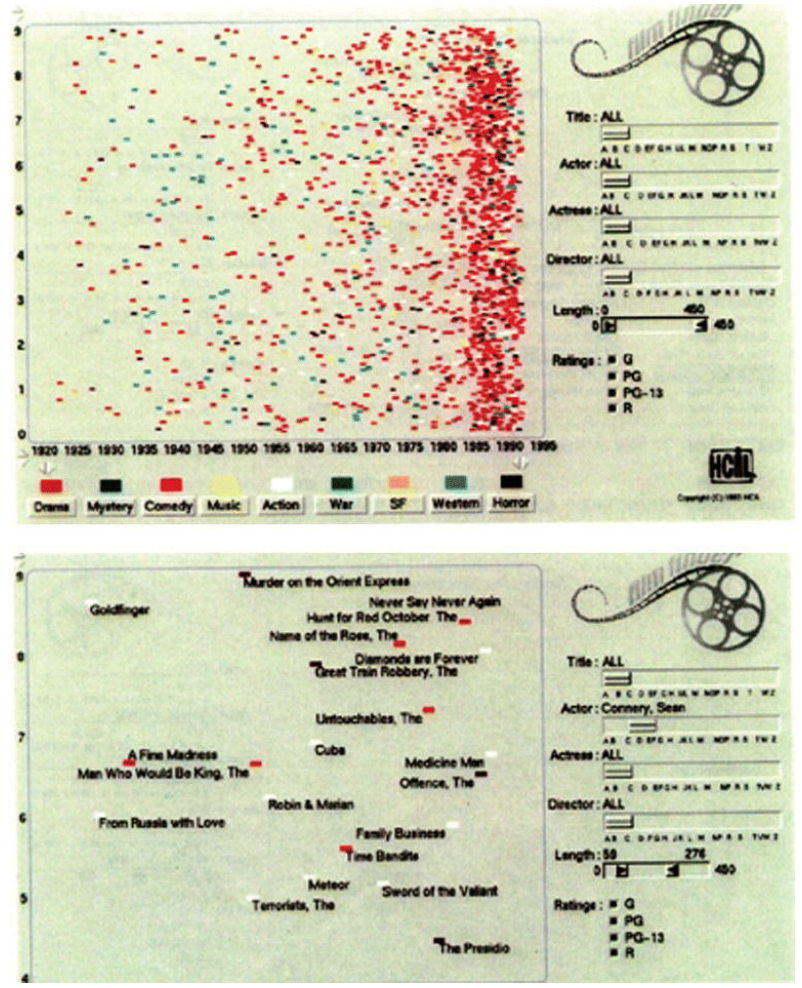

Figure 1. The Film Finder.

\section{PLIABILITY IN ACTION}

The notion of pliability is an attempt to articulate a certain quality in using digital, interactive products and services. The use of a digital artifact is characterized as pliable if it feels like a tightly connected loop between eye and hand, between action and response. A pliable interaction is one where the user is drawn into a sense of shaping the digital information with his/her fingertips, even though the actual artifact might employ standard, non-tactile interaction techniques such as mouse, keyboard, and display monitor. Pliability is a sensuous quality, having to do with how it feels to use the artifact in the hereand- now of the use situation, and as such it plays a role in understanding the aesthetics of interaction. This topic will be addressed further in the concluding discussion; the current section starts with a brief historical sketch and then moves on to an analysis of a number of digital artifacts from three different domains: online maps, digital-image management, and online thesauri. Within each domain, I have chosen examples that range from less pliable to more pliable, and it is my intention that the reader's understanding of pliability will be furthered through the examples and my discussion of them rather than by abstract definitions.

In the late 1980s, the use of databases was largely stereotyped as follows: you start with an empty search form, you type in your search criteria, you hit the Search button, you wait for a while, you receive a set of results that correspond to the criteria you entered (and also, it is hoped, to the intentions you had when searching the database). The overall character of the interaction was coarsegrained and stilted, essentially performed on the computer's terms. Ben Shneiderman, Christopher Ahlberg, and their colleagues at the University of Maryland identified the stereotype of database use as dissonant with contemporary ideas of interactive information visualization as a captivating and exploratory experience. Shneiderman had generated the initial idea of visual dynamic queries and together with his coworkers produced a range of prototypes where the concept was refined for different applications. One of them was the FilmFinder from 1993 shown in Figure 1 (Ahlberg \& Shneiderman, 1994; see also Shneiderman, 1999, for more on the historical background).

FilmFinder contains information on some 1500 video films. In the starting state, each movie is plotted as a colored dot with production year on the $\mathrm{X}$-axis and popularity on the $\mathrm{Y}$-axis. One might say that FilmFinder turns the regular movie database inside out: Instead of starting with an empty search form, it starts by showing the full dataset. Instead of searching, the user locates movies of interest by gradually applying filters through manipulating the gauges in the right half of the interface. For instance, if I start dragging the left knob of the duration gauge from its starting position at 0 minutes and to the right, what happens is that some of the colored dots disappear from the plot as I increase the lower bound of the duration filter. When I have reached 
the point of, say, 180 minutes, only the dots remain that represent movies with a duration greater than three hours. Several filters can be combined to locate, for example, all movies longer than three hours that were recorded before 1980 with Charlton Heston as the male lead actor (epic of all epics: Ben Hur!).

The whole point of dynamic queries is that every minute manipulation of the filters is instantly reflected in the plotted dataset. The connection between action and response feels very close and there is a certain sense of physically shaping the digital information, which can be quite captivating. ${ }^{1}$ Moreover, the fine-grained interaction may lead to discovery of unexpected regularities in the dataset. For example, I might discover while increasing the lower bound for duration that dots in the left half of the plot tend to disappear first, which would mean that short films were more common in the early history of movie production. This is perhaps not a revolutionary insight in itself, but it illustrates how more fine-grained interaction can create conditions for what is known as serendipitous discovery, i.e. to learn things about the dataset you didn't know you were interested in.

Dynamic queries are on some level instrumentally equivalent to conventional database queries: they enable the user to locate information in a relational database. However, their experiential qualities in use are quite different. For my purposes, the difference captures the basic quality of pliability rather well. I will now continue adding to the picture by discussing a range of contemporary digital artifacts and their pliability (or lack thereof).

\section{Geographical information}

The first set of examples concerns online searching for geographical information presented through maps. Figure 2 illustrates a typical yellow-pages website: you type in an address or the name of a company, institution, or landmark, you press Search, the result is presented on a map, you navigate the result by panning and zooming. This particular example was taken from the Swedish yellowpages site Eniro in April 2006 and it was a good representative of a large class of similar websites at the time of writing.

The widespread geographical information service Google Maps is instrumentally identical to Eniro: type in search criteria, get result on map, navigate map, etc. However, they used to feel quite different in use. Navigating the Eniro map in the spring of 2006 was a clunky and large-grained interaction experience, where panning was accomplished by clicking the red frame of the map, waiting while the image updates, then concentrating hard to find the landmarks and reconcile the new view with the previous one. Zooming was similarly largegrained, with clicking on the zoom control and then waiting for the updated image to appear. In contrast, the Google map could be panned by dragging it with the mouse, which strongly enforced my sense of tactile involvement with the information and eliminated the effort of perceptual reconciliation. If I should prefer to use the pan buttons, the transition was animated reasonably smoothly, which again facilitates view reconciliation. Satellite images are combined with map information to emphasize the physical reality underlying the geographical information service. Zooming in Google Maps is regrettably no more fine-grained than in Eniro, probably for technical performance reasons. The net result, however, was that Google Maps illustrated a more pliable approach to geographical information services than Eniro, mainly due to its superior interaction technique for panning and its integration of photographic imagery with the symbolic iconography of regular maps. It is probably no coincidence that Eniro, like virtually any other online map service on the web, has implemented direct-manipulation panning and satellite photographs in the last year.

A further step towards pliability is illustrated by Google Earth (Figure 3). The main difference compared with previous examples is that the third dimension is integrated in the design throughout. Zooming is no longer a tedious and instrumental operation of increasing map resolution to find the requested geographical information, but rather a visceral experience of traveling from outer space all the way down to the face of the earth (i.e. the map) at dizzying speed. The threedimensional representation also allows me to adjust the tilt of the camera and fly over the mountains; some regions have additional data such as $3 \mathrm{D}$ models of buildings and topography, which add further to the experience, and at large distances panning becomes perceptually equivalent to spinning the globe with your fingertips. In short, Google Earth is a highly pliable interface to geographical information. This quality comes at a price, of course, and in this case the price is that the user has to download and install a separate client in order to achieve the level of graphics performance and responsiveness needed to provide the richer experience.

The three examples so far all rely on standard interaction techniques: a mouse, a keyboard, and a display monitor. Other examples exist that illustrate the tactile nature of pliability and provide more literal interpretations of what the use experience of "shaping the digital information with your fingertips" might entail. The Multi-Touch Interaction technology by Han (2005) demonstrates how far a touchscreen can be pushed in terms of resolution and responsiveness. One of the MTI demos shown in the video (Han, 2006) is a geographic information service that appears to be very similar to Google Earth in terms of functionality (Figure 4). The impression you get from the video, however, is that two-handed input directly on the display surface adds even more pliability to the use experience.

\section{Digital image management}


ge Eniro - Kartor - - Microsoft Internet Explorer

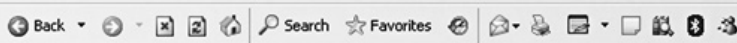

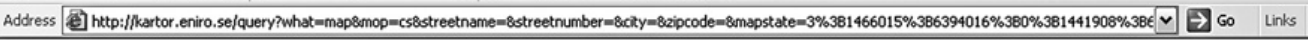
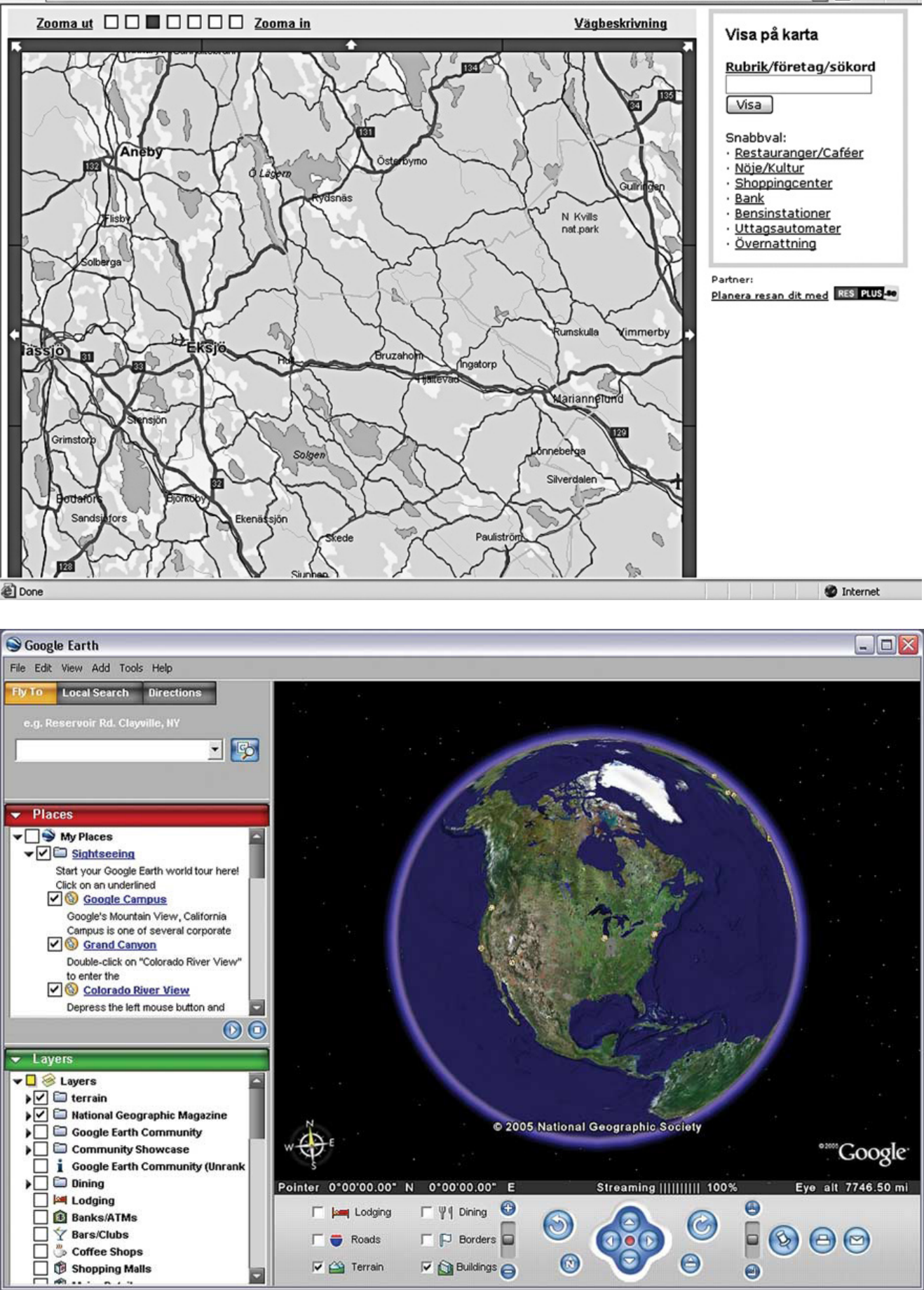

Figure 2

The online map service at www.eniro.se as per April 2006. By permission of Eniro.
Figure 3.

Google Earth (available from earth.google.com). By permission of Google. Image \# 2005 National Geographic Society.
My second set of examples concerns application programs for domestic, non-professional management of images from digital cameras. The scenario is very familiar: We have bought a digital camera and started taking a lot of pictures, and now we need something for the home computer to take care of all the pictures: collect them, sort them, share them with friends, print a few of them, make birthday party invitations, have some professionally printed to put in picture frames, make sure we have solid backups in case the home computer crashes, and so on.
Several programs are available to offer this kind of digital-image management services. Two widespread examples are ACDsee from ACD systems and Picasa from Google, shown in Figures 5 and 6 . Broadly speaking, they offer the same functions from an instrumental point of view, yet they are quite different in terms of how it feels to use them.

The screenshots display some similarities between the two programs, which are also typical of most programs in this category. There is a large central surface on which a current selection of images is 
presented. There is a folder structure on the left, providing access to places on the disk where images are stored. There are a number of functions related to image manipulation and management of image collections.

We also notice a few differences, the most striking one in the screenshots being that ACDsee looks like a typical Windows program whereas Picasa has a more calm and unified look. The choice of colors, typefaces, and graphical elements contributes to this impression, as well as the sensible decision to let the images themselves dominate the central surface with all unnecessary visual clutter such as frames, icons, and filenames removed. Another reason for the more calm expression of Picasa is the strong separation of functions into different modes, displaying only the functions that are relevant in each mode.

What I would like to concentrate on here, however, is how it feels to manipulate collec- Figure 4. MultiTouch Interaction applied to map information. tions of images in the two programs. ACDse uses conventional Windows controls for scrolling the central surface and for navigating among pictures in detail view. The use is certainly predictable but not in any way remarkable. You can do what you want to get done but there is nothing in the use experience that would make you smile or think appreciatively of the handling in itself.

Picasa, on the other hand, represents an extraordinary attention to interaction details, which may individually seem insignificant but jointly contribute to an aesthetically superior experience. The zoom control in the lower right offers continuous and smooth zoom of the pictures in the main surface. The up and down arrows of the scroll bar activate an animated ease-in and ease-out which both feels good and reinforces the sense that all my images are kept in a coherent collection on the main surface. The scroll bar is augmented with an innovative knob (resting in the middle of the scroll bar in Figure 6) that controls the scrolling speed in both directions. If you grab the knob and move it slightly off-center, the main surface will start scrolling slowly. As you drag the knob further, the main surface scrolls faster. The close connection between action and response contributes to a stronger sense of tactility and multisensory stimulation - in short, to pliability.

\section{Online thesauri}

Most people who write texts also use a thesaurus occasionally: to find the just-right synonym, to create a little variation, or to locate that word we know so well but fail to recall while writing. A thesaurus is essentially an alphabetically ordered compilation of synonyms and the way we tend to think of thesauri is shaped by library reference books with many pages and heavy covers, printed on bible-thin paper in slightly quaint typography. A thesaurus seems authoritative, and the most widespread online adaptations generally follow the stereotype (Figure 7).

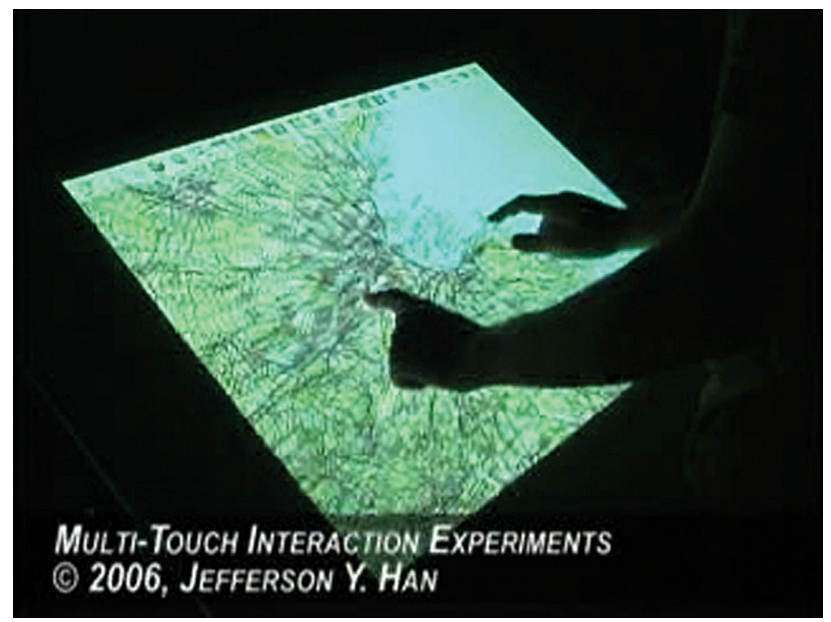

Figure 4

Multi-Touch Interaction applied to map information.

The use of an online thesaurus such as the one at reference.com is similar to a classical database search as discussed earlier: enter the word to search for, wait for a bit, receive a set of search results, and browse through the results by scrolling to find the synonym you need. The interaction can be characterized as rather coarse-grained and nondescript, driven by the lexicographic contents of the underlying databases.

The Visual Thesaurus, on the other hand, illustrates a dramatically different interface to what is essentially the same underlying database contents (Figure 8). It was launched on the web by Plumb Design in 1998 or 1999 as a free online thesaurus, and then remade into a commercial service with a revised graphical interface in $2003 .^{2}$

You start a Visual Thesaurus search by typing a word and clicking Search just as in any other online thesaurus - but then the paths differ. The search results are presented visually as a network with the search word in the middle and the synonyms hovering around it, moving subtly but not so much that they are hard to click on. And when you click on one of the synonyms it moves gracefully to center stage, dragging its synonyms along with it and pushing the previously selected word out to the edge. The feel of the transition is pleasant enough to encourage a few extra clicks and hence a bit of unanticipated browsing in the network formed by the synonymic relations. What is more, the dynamic and tactile nature of the browsing experience might start undermining the notion of thesauri as authoritative tomes, in favor of a growing sense of language as a more volatile and temporary construction of socially shared meaning (which is, linguistically speaking, a much more accurate understanding). Khaslavsky \& Shedroff (1999) discussed the captivating use experience of the Visual Thesaurus shortly after it came out as an example of what they called seductivity; for me, comparing it with conventional online thesauri is an excellent way to under stand what pliability might mean for the use experience.

\section{DISCUSSION}



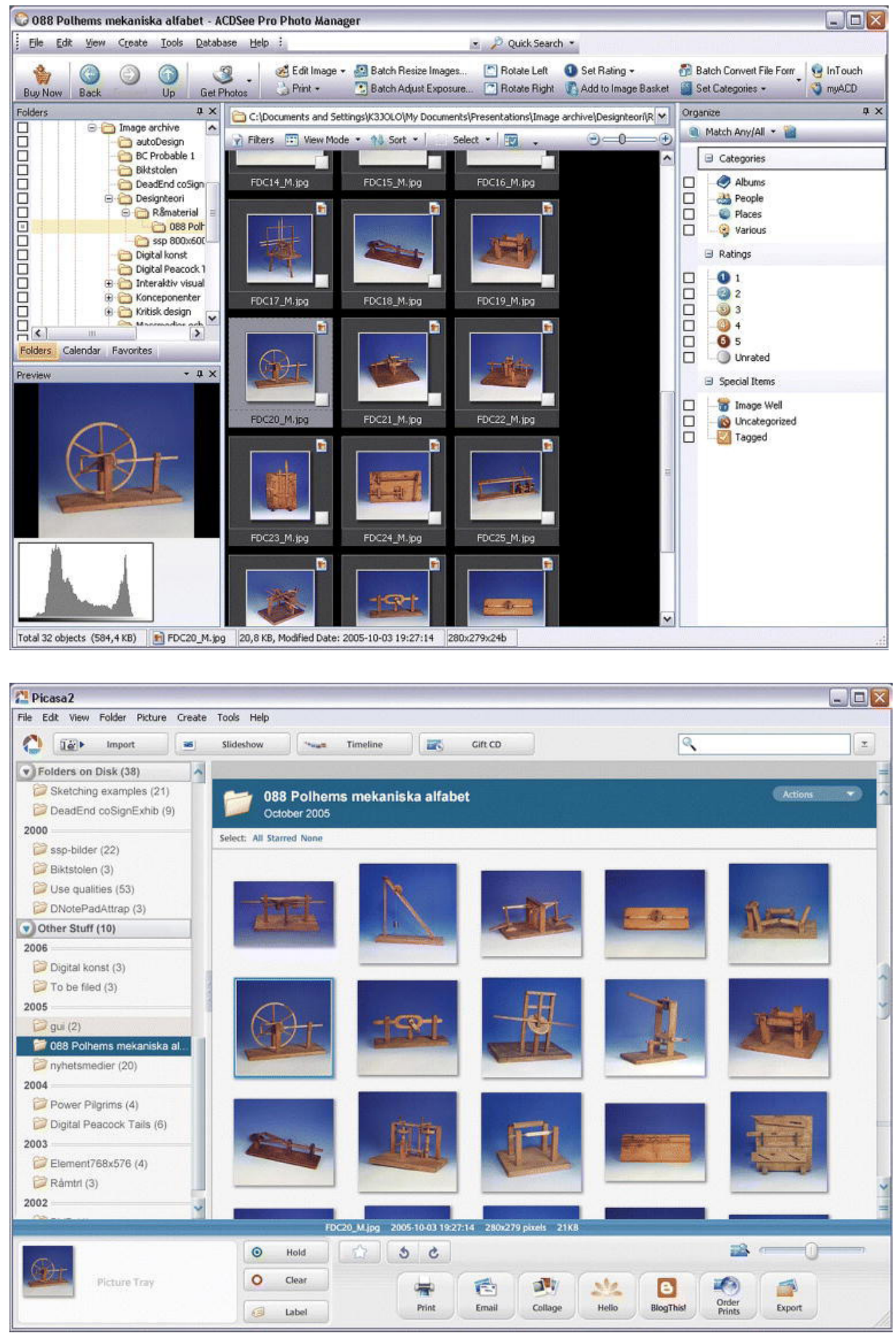

Figure 5.

ACDsee from ACD Systems (www.acdsystems.com). By permission of ACD Systems.
Figure 6.

Picasa from Google (picasa. google.com). By permission of Google.
Online maps, digital-image management tools, and online thesauri are all examples of everyday digital products that are typically regarded instrumentally. This means that they are assessed in terms of efficiency and fitness-forpurpose: are the provided functions useful, can they be used easily and efficiently, do they support me in doing what I want to get done without errors or hang-ups? I have tried to argue that there is also an experiential/ aesthetic dimension at play in their use, consisting of temporal and visuo-tactile qualities such as pliability. Moreover, I have tried to show how common products that are essentially equivalent in instrumental terms can be quite different in experiential terms, and how the concept of pliability seems to clarify the nature of the differences among the examples I have chosen. To summarize so far, pliability characterizes the extent to which the user perceives an interaction to 
be fine-grained with a tight coupling between action and outcome, a pseudo-tactile sense of manipulating a malleable digital material. Google Earth is more pliable than the maps at Eniro. Picasa is more pliable than ACDsee. The Visual Thesaurus is more pliable than the reference.com thesaurus. (Or, to be more precise: their use tends to be perceived as more pliable - but more on this below.)

\section{The scope of pliability}

An obvious question to lead off the discussion, then, is when pliability is desirable. Under what circumstances should an interaction designer explicitly aim to make the user feel a sense of pliability in the use of the new product? One way of approaching the question might be to introduce the notion of design genres. It has been suggested (Hult, 2003) that experiential qualities comprise one of the factors that constitute genres in interaction design. In other words, a specific combination of experiential qualities may be identified or proposed as the key qualities for designers to strive for in the design of products belonging to a specific class, or genre. For example, Hult's own work concerned the genre of online encyclopedias, where he found empirically that some of the distinguishing experiential qualities were timeliness, precision, and credibility. Analogically, all the examples presented in this paper to illuminate the concept of pliability can be said to belong to the interaction design genre of interactive visualization.

I would argue that pliability is one of the desirable experiential qualities in the use of interactive visualizations, and hence something that designers of interactive visualizations should strive to facilitate. I have hinted earlier at the tendency of more pliable interactive visualizations to encourage exploration of the underlying data and to create conditions for serendipitous discoveries - i.e. during the interaction, the user might learn things he/she didn't look for and didn't know he/she was interested in learning:

[Google Earth] is so full of possibilities that it is hard to let go of it. I tend to lose myself for hours in it, looking for places I have been to and places I long to visit. Seeing them from above and zooming in on the details creates a desire to travel and a number of very pleasant fantasies. Tonight, I am planning to recreate a hike I did in the Alps last autumn to see if I can find that special hotel with the balcony facing the snow-sparkling peak of Mont Blanc.

The quote is translated from a recent column in Sweden's largest weekly technology magazine (Melin, 2006). The columnist, who is not an interaction designer but rather an early-adopter kind of user writing for a general audience, addresses the captivating qualities of Google Earth and essentially writes about exploration and serendipity, which I would attribute in turn to the pliability of the use experience. Furthermore, user studies of the original dynamic query interfaces (Ahlberg \& Shneiderman, 1994) support the claim that what Ahlberg \& Shneiderman call tight coupling (which is very closely related to my notion of pliability) seems to facilitate exploratory behavior and serendipitous discovery. Another piece of empirical support comes from my work with the Sens-A-Patch interaction technique (Figure 9), which I designed a few years ago in order to explore pliability in some depth (Löwgren, 2001). I performed a user study to compare a Sens-A-Patch website front page with a static layout containing the same information. It turned out that the two interfaces were equivalent with regard to accuracy and speed in tasks of locating requested information on the website. However, the users spent significantly more time with the Sens-APatch interface in free exploration tasks and found it more aesthetically pleasing, characterizing it in metaphorically tactile terms as a fluent experience akin to painting with watercolor.

\section{Related work}

Another way of assessing the proposed notion of pliability is to relate it to similar concepts. As should be clear, pliable interaction has an immersive element to it: the tight connection between action and outcome, the pseudotactile sense of manipulating the interface and shaping the information, the sense of being drawn into the material under exploration - all of this points to a rather highly involved and immediate experience at the focus of attention. I have already mentioned the closely related concept of tight coupling, which is Ahlberg \& Shneiderman's way of trying to capture the essential quality of their dynamic queries. However, any further discussion requires an introductory and important note, namely that this immersion does not presuppose a division between "interface" and "con tents", but rather recognizes the impossibility of such a division.

Humancomputer interaction research in the early 1990s idealized the notion of transparency, taken to mean that the "interface", i.e. the controls or manipulation tools, should disappear in use to enable the user to engage directly with the "contents", the "purpose" of the interaction (see, e.g., Bødker, 1991). Situations where the "interface" reappeared were seen as breakdowns or disruptions, typically analyzed in Heideggerian terms as instances of the tool going from ready-tohand to present-at-hand. A recent example of similar thoughts is Krippendorff 's (2006) model of artifact use involving the three following modes of attention: recognition (identifying what something is and what it can be used for), exploration (figuring out how something works), and reliance (handling something so naturally that attention can be focused on the sensed outcomes). 


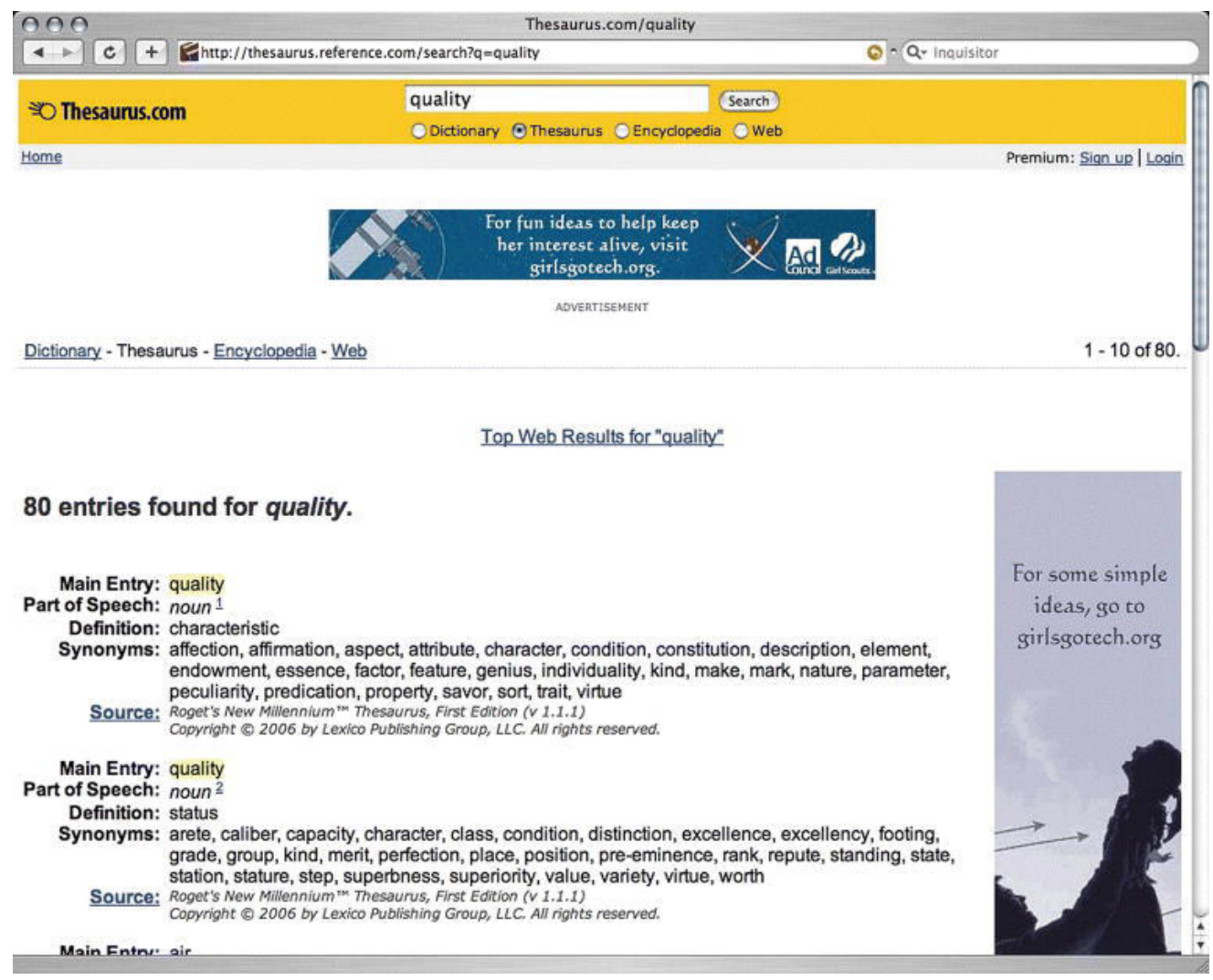

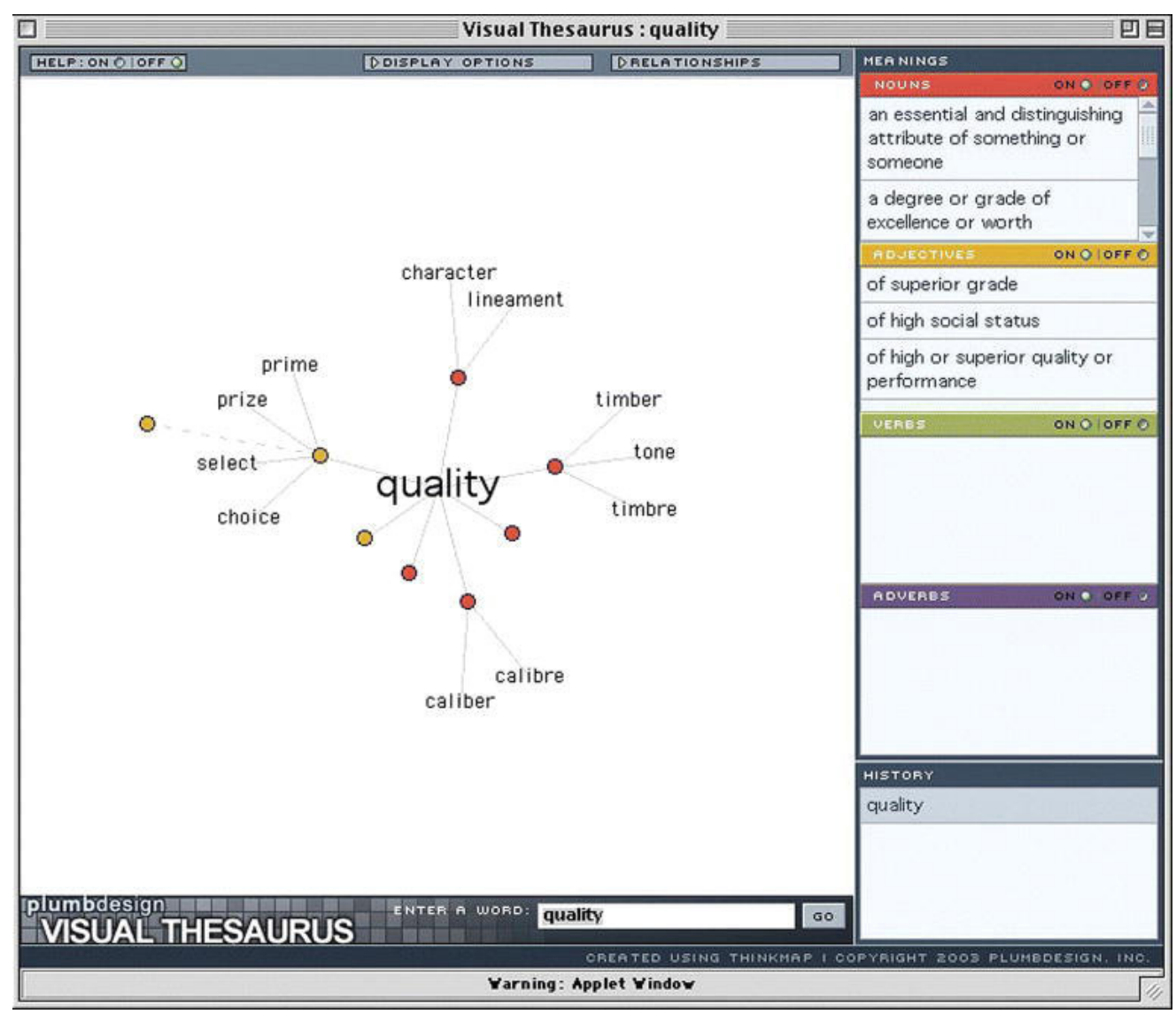

Figure7.

The online thesaurus at thesaurus.reference.com By permission of Lexico.
Figure 8.

The Visual Thesaurus (www. visualthesaurus.com). (C)1998-2007, Thinkmap, Inc. All rights reserved. Used by permission of Thinkmap. 
The examples I have used above to explore the notion of pliability, however, seem to mix exploration and reliance - and even make a virtue out of it. Consider the way I discuss zooming in Google Earth as a visceral experience. Or the qualities of the augmented Picasa scroll bar. Or the subtle animations in the Visual Thesaurus. These are all examples of how properties of the tools, the "interface", come to the fore of the user's attention but not in detrimental or disruptive ways. Pliability as I have introduced it here concerns the experience of using the whole artifact, where "interface" and "contents" are not different levels of abstractions but merely two aspects of the same experience. The flow of the experience (Csikszentmihalyi, 1997) is not confined to reliance, as suggested by Krippendorff, but rather rests on the graceful synthesis of exploration and reliance. In Laurel's (1991) prescient terms, what counts is the feeling of participating in the action of the representation (conflating "interface" and "contents"). The pleasure of pliability is found in the feel of the tools as well as in the outcomes they produce. This is a crucial point when it comes to relating pliability to other notions of highly involved interaction emerging from the field of $\mathrm{HCl}$. For a further discussion of "the myth of transparency", refer to Bolter \& Gromala (2003).

In the interest of completeness, it should also be mentioned that the term pliability has been used by other interaction design researchers in a slightly different way. Henderson \& Harris (2000) discuss pliability in the context of administrative information systems as the possibility for information workers to shape their information artifacts more flexibly. Their example concerns digital forms compared with paper forms, where digital forms are found to be rigid and limiting compared with the pliability of paper forms: A clerk can fill in a paper form in ways other than the stipulated ones, relying on the interpretive capability of the recipient; he/she can make notes in the margins; he/she can affix sticky notes to the form, and so on. Henderson and Harris argue in favor of similar flexibility also in the case of digital information work. I would suggest using the qualified term "deep pliability" here, and speak of "surface pliability" or "interaction pliability" if necessary to distinguish the sense of the term I have introduced in this paper.

To conclude the section on related work, recall that I have called pliability an aesthetic quality and argued for the importance of aesthetic experience also in the use of everyday products normally assessed in instrumental terms. Udsen \& Jørgensen (2005) have recently presented an admirable survey of what they term "the aesthetic turn in humancomputer interaction". They outline four approaches, including the cultural approach drawing on the humanities and media studies, the functionalist approach based on traditional $\mathrm{HCl}$, the experience-based approach of interaction design, and the techno-futurist approach based on philosophy. Using this taxonomy, the work I present here with its rather detailed focus on use experience falls squarely within the experiencebased approach to aesthetics. However, the way in which I have tried to choose examples carefully and develop the concept of pliability through a close "reading" of the examples is inspired by analysis methods typically found within the cultural approach (see, for example, Engholm's [2004] analysis of the aesthetics of everyday websites).

\section{Comments on "method"}

The preceding discussion indicates that pliability is a worthwhile experiential quality for designers and researchers to explore and articulate. The joint evidence seems to suggest that a conscious aim to create conditions for pliability can contribute to better practical design of interactive visualizations.

But what do I mean when I use the phrase to "create conditions for pliability"? The reason for this circumscription is that pliability is an example of an experiential quality, something that characterizes a person's use of a digital artifact to a greater or lesser degree. As such, it is relational- pliability is not a property of the artifact itself, nor is it a psychological or physiological property of the user. Pliability appears in use.

Strictly speaking, this means that an interaction designer cannot design a pliable product. What he/ she can do, however, is to design conditions for pliability to appear in the subsequent use of the product. This is merely an instance of a more general argument that follows from a design focus on use and use experience: You can never design a product that possesses a certain quality, but you can design to increase the chances that the use of the product will be experienced in a certain way.

If this is the case, then it seems appropriate to conclude the paper by asking the metaquestion of how knowledge can be articulated and disseminated to enable members of the design community to increase their chances of facilitating certain use experiences. Specifically, how can designers, researchers and critics communicate about pliability in a way that puts other designers in a better position to design for pliable use?

This paper is an attempt to illustrate a tentative answer to that question. By presenting a set of contrasting examples of artifacts that tend to exhibit more or less pliability in use, by articulating the use experiences of those examples with particular emphasis on pliability, and by relating the concept of pliability to other authors' articulations of similar experiential qualities, my intention is to provide material that other designers can use in the ongoing development of their own design ability.

More generally, my approach is based on a notion of a design community as a discursive, knowledgeconstructing social structure (Löwgren \& Stolterman, 2004; Krippendorff, 2006). To me as a designer and researcher, it seems fruitful to think of designers, critics, and researchers in a certain design field as members of a community sharing an interest in developing the field towards better products and 


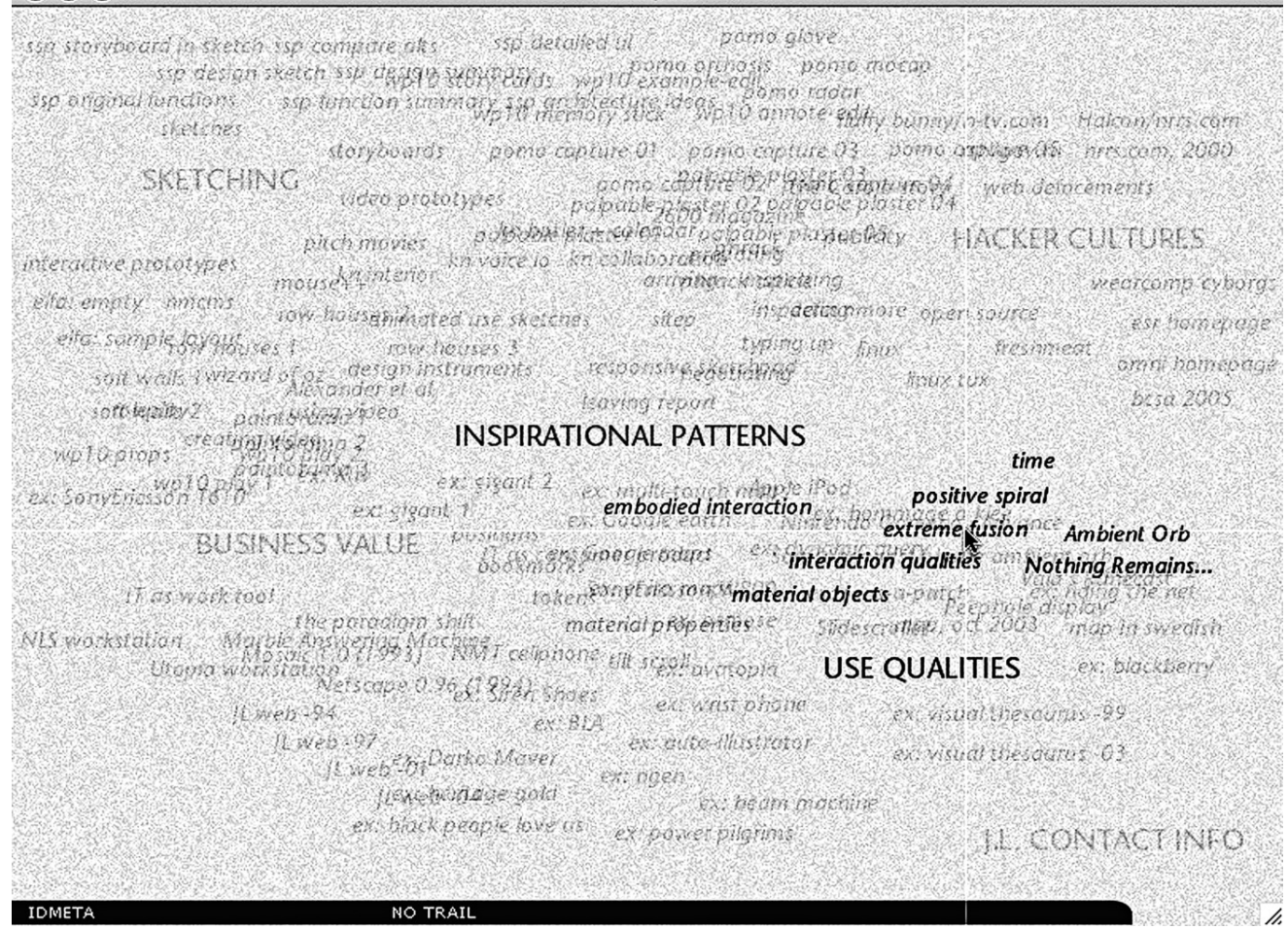

Figure 9 .

Sens-A-Patch used as main interaction technique in the Slidespace application for managing and presenting slides during a talk. See webzone.k3.mah.se/ k3jolo/Sens-A-Patch/ and webzone.k3.mah.se/k3jolo/ Slidespace/ for more information and downloads.

practices (as opposed to "merely" serving clients and earning financial rewards for the efforts). Such a community is characterized by an ongoing debate in open and accessible fora, where statements in the form of design ideas, principles, experiences, analytical concepts, etc., are put forth, challenged, qualified, refused, revised, and supported. I have argued elsewhere (Löwgren, 2006) that the articulation of experiential qualities can be beneficial in practical design by guiding upstream design work and by facilitating communication with non-designer stakeholders; here, I would like to close with a comment on the epistemological potential of the work.

Attempting to articulate an experiential quality of design, presenting it in an accessible way, accounting for its relations to related concepts and empirical evidence, and indicating its scope of applicability should be seen as a proposed statement in the ongoing community work of knowledge construction. Specifically, I have offered the concept of pliability as a contribution to the emerging body of knowledge in interaction design. My intentions in this work are twofold.

First, I hope that other community members (interaction designers, researchers, and critics) will react to pliability by challenging the concept, trying to use it in practical design, finding better examples, refining the definition, reflecting on their own design work, and so on.

Second, a more ambitious aim is for a community discourse to grow on other temporal and visuotactile experiential qualities, ultimately leading to a body of knowledge emerging on the materialspecific aesthetics of interaction design. So far, this topic is largely a white spot on the knowledge map of interaction design, and the urgency to start filling it grows with the increasing discretionary use of ubiquitous digital artifacts. To put it simply, when people are surrounded by digital products and services that they can choose freely between (or choose not to use), aesthetic qualities are becoming every bit as important as the instrumental ideals of the human computer interaction tradition originating - the 1980s and still pervading the field of interaction design.

My hope is thus that designers, critics, and researchers engage in the ongoing construction of knowledge concerning the aesthetics of interaction design, eventually contributing to more rewarding experiences of using digital artifacts.

\section{NOTES}

1. A video showing the FilmFinder in use can be found at http:// www.cs.umd.edu/hcil/pubs/video94.shtml. My general recommendation when trying to understand the dynamics of digital artifacts, including the ones I discuss here, is to try them out. Some are hard to get hold of for various reasons - the second best option is to watch a demonstration. Many designers and researchers fortunately make significant efforts to provide demo videos on the web.

2. The company is now called Thinkmap and markets the visualization engine driving the Visual Thesaurus as a general way to present various kinds of interlinked information (http://www. thinkmap.com).

\section{REFERENCES}

Ahlberg, C., \& Shneiderman, B. (1994). Visual information seeking: Tight coupling of dynamic query filters with starfield displays. Human Factors in Computing Systems (CHI ‘94 Proceedings) (pp. 313-317). New York: ACM Press. 
Bødker, S. (1991). Through the interface: A human activity approach to user interface design. Hillsdale, NJ: Lawrence Erlbaum.

Bolter, J., \& Gromala, D. (2003). Windows and mirrors: Interaction design, digital art and the myth of transparency. Cambridge, MA: MIT Press.

Csikszentmihalyi, M. (1997). Finding flow: The psychology of engagement with everyday life. New York: Basic Books.

Dewey, J. (1934). Art as experience. New York: Perigee.

Engholm, I. (2004). Webgenrer og stilarter. In I. Engholm, \& L. Klastrup (Eds.), Digitale verdener: De nye mediers æstetik og design (pp. 57-77). København: Gyldendal (in Danish).

Fels, S. (2000). Intimacy and embodiment: Implications for art and technology. Proceedings of the ACM Workshops on Multimedia (pp. 13-16). New York: ACM Press.

Han, J. (2005). Low-cost multi-touch sensing through frustrated total internal reflection. Proceedings of ACM User Interface Software and Technology (UIST) (pp. 115-118). New York: ACM Press.

Han, J. (2006). Multi-touch interaction experiments. Video available at: http://www.mrl.nyu.edu//jhan/ftirtouch/, map demo at timecode 1:38-2:13 (accessed 16 March 2006).

Henderson, A., \& Harris, J. (2000). Beyond formalism: The art and science of designing pliant systems. In K. Kaasgard (Ed.), Software design and usability. Copenhagen: CBS Press.

Hult, L. (2003). Publika informationstjänster: En studie av den Internetbaserade encyklopedins bruksegenskaper [Public information services: A study of use qualities in Internet-based encyclopedias.] Ph.D. dissertation, Linköping University, Sweden (In Swedish).

Jordan, P. (2000). Designing pleasurable products: An introduction to the new human factors. London: Danish Centre for Design Research.

Khaslavsky, J., \& Shedroff, N. (1999). Understanding the seductive experience. Communications of the ACM, 42(5), $45-49$.

Krippendorff, K. (2006). The semantic turn: A new foundation for design. Boca Raton, FL: CRC Press.

Laurel, B. (1991). Computers as theatre. Reading, MA: AddisonWesley.

Löwgren, J. (2001). Sens-A-Patch: Interactive visualization of label spaces. In E. Banissi et al. (Eds), Proceedings of the Fifth International Conference on Information Visualization (IV2001) (pp. 712). Los Alamitos, CA: IEEE Computer Society.

Löwgren, J. (2006). Articulating the use qualities of digital designs. In P. Fishwick (Ed.), Aesthetic computing (pp. 383-403). Cambridge, MA: MIT Press.

Löwgren, J., \& Stolterman, E. (2004). Thoughtful interaction design: A design perspective on information technology. Cambridge, MA: MIT Press.

McCarthy, J., \& Wright, P. (2004). Technology as experience. Cambridge, MA: MIT Press.

McCullough, M. (1996). Abstracting craft: The practiced digital hand. Cambridge, MA: MIT Press.
Melin, J. (2006, January 18). Örnkoll på alptoppen. Ny Teknik (in Swedish).

Norman, D. (2004). Emotional design: Why we love (or hate) everyday things. New York: Basic Books.

Petersen, M., Iversen, O., Krogh, P., \& Ludvigsen, M. (2004). Aesthetic interaction: A pragmatist aesthetics of interactive systems. Proceedings of the Conference on Designing Interactive Systems (DIS '04) (pp. 269-276). New York: ACM Press.

Shneiderman, B. (1999). Dynamic queries, starfield displays, and the path to Spotfire. Manuscript, retrieved March 10, 2006, from http://www.cs.umd.edu/hcil/spotfire/.

Udsen, L., \& Jørgensen, A. (2005). The aesthetic turn: Unravelling recent aesthetic approaches to humancomputer interaction. Digital Creativity, 16(4), 205-216.

\section{CORRESPONDENCE}

Correspondence: Jonas Löwgren,

School of Arts and Communication,

Malmö University,

20506 Malmö, Sweden.

E-mail: Jonas.Lowgren@k3.mah.se

ISSN 1749-3463 print/ ISSN 1749-3471

DOI: $10.1080 / 17493460600976165$

(C) 2007 Artifact 